\title{
Ganho de Peso de Novilhos Mantidos em Pastagem Natural na Encosta do Sudeste do Rio Grande do Sul, Recebendo Níveis Crescentes de Suplementação Energética ${ }^{1}$
}

\author{
Vivian Fischer ${ }^{2}$, René Mauricio Patiño Pardo ${ }^{3}$, Maira Balbinotti Zanela ${ }^{4}$, Claiton Baes Moreno ${ }^{5}$, \\ Everson Xavier Ferreira ${ }^{6}$, Pedro Lima Monks ${ }^{7}$
}

\begin{abstract}
RESUMO - O experimento foi desenvolvido com a finalidade de avaliar os efeitos de suplementação energética com sorgo moído sobre o desenvolvimento corporal de novilhos de corte em pastejo. Sessenta e cinco novilhos (12 a 15 meses de idade, sem raça definida, com $140 \mathrm{~kg}$ de peso vivo médio) foram mantidos em pastejo contínuo em uma pastagem natural melhorada com Lotus subbiflorus e invadida por Eragrostis planna, Ness. Os tratamentos consistiram de controle (T0), sem suplemento; 0,75\% do peso vivo (T0,75); e 1,5\% do peso vivo (T1,5) de grão de sorgo moído fornecido. Os animais foram distribuídos aleatoriamente nos tratamentos, segundo o delineamento completamente casualizado. Na média geral do experimento, houve efeito linear dos níveis de suplemento sobre o ganho de peso diário, de 0,36; 0,52 e 0,76 kg/animal/dia, respectivamente, para os tratamentos T0, T0,75 e T1,5. A suplementação energética permitiu maior ganho de peso nos animais suplementados em relação aos controle, durante todo o período experimental.
\end{abstract}

Palavras-chave: ganho de peso, grão de sorgo, pastagem natural

\section{Increasing Levels of Energy Supplementation on Weight Gain of Grazing Steers Kept on a Natural Pasture at the Southeastern Region of Rio Grande do Sul}

\begin{abstract}
The trial was conducted to evaluate the effects of energy supplementation with ground sorghum grain on grazing beef steers weight gain. Sixty five steers without definite breed, aging 12 to 15 months and weighing an average $140 \mathrm{~kg}$ of live weight were kept under set stocking on a natural pasture improved with Lotus subbiflorus. Treatments consisted of control or without supplement (T0); $0.75 \%$ of mean live weight (T0.75) and $1.5 \%$ of mean live weight (T1.75) of ground sorghum grain. Animals were randomly assigned to treatments according to a complete randomized design. Considering the overall mean of the trial, supplement levels showed a linear positive effect on daily weight gain, of $0.36,0.52$ and $0.76 \mathrm{~kg} / \mathrm{animal}$ for T0, T0.75 and T1.5, respectively. Energy supplementation resulted in greater weight gains for supplemented animals compared to not supplemented animals, during all the experiment.
\end{abstract}

Key Words: natural grassland, sorghum grain, weight gain

\section{Introdução}

No Rio Grande do Sul, as pastagens naturais ocupam cerca de 12 milhões de hectares, aproximadamente $44 \%$ de sua superfície total e se constituem na principal fonte de forragem dos 14 milhões de bovinos e 7 milhões de ovinos criados no Estado. Entre as principais características dessas pastagens, destaca-se a grande diversidade de espécies, com cerca de 800 espécies de gramíneas e 200 espécies de leguminosas, com ciclo predominantemente estival (Mohrdieck, 1980).
A variação sazonal quantitativa e qualitativa da produção dos pastos nativos do RS é reconhecida há vários anos. Entre as causas desta sazonalidade, pode-se citar a sua composição botânica (Jacques et al., 1995). A predominância das espécies estivais, que diminuem drasticamente a sua velocidade de crescimento sob temperaturas abaixo de $15^{\circ} \mathrm{C}$ é uma das causas da redução de oferta de pastagem, durante os meses de outono e inverno. Além disto, durante o período frio, a maioria das plantas se encontram no estádio final da formação de sementes, o qual se caracteriza por elevada concentração de parede celular e baixos

\footnotetext{
1 Pesquisa financiada pela FAPERGS, PPGZ-UFPEL e Parceria agropecuária Piratini.

2 D.Sc. Produção Animal, Professor Adjunto Departamento de Zootecnia UFPEL, Bolsista do CNPq, Pelotas - RS - CEP: $96010-970$ vfried@portoweb.com.br; vfried@ufpel.tche.br

3 Zootecnista, Mestre em Produção animal pela PPGZ-UFPEL, residente na Colômbia.

${ }^{4}$ Aluno curso de doutorado PPGZ - UFPEL.

5 Aluno do curso de medicina veterinária, bolsista de Iniciação Científica - FAPERGS.

${ }^{6}$ Aluno do curso de medicina veterinária, bolsista de Iniciação Científica - CNPq.

${ }^{7}$ D.Sc. Produção Vegetal, Professor Adjunto Departamento de Zootecnia UFPEL.
} 
teores de proteína bruta e de digestibilidade, ocasionando restrição no consumo voluntário. No entanto, durante a estação quente, ocorrem períodos variáveis de estiagem, que diminuem a produção forrageira. A quantidade e a qualidade dos campos naturais podem variar durante a estação de crescimento (Abdalla et al., 1988), o que pode ser comprovado pela distribuição irregular do ganho de peso dos animais durante os meses de primavera-verão (Moojen, 1991; Correa, 1993).

O desempenho animal depende, em sua maior parte, 60 a 90\%, do consumo de matéria seca, posto que as diferenças na digestibilidade dos alimentos influenciam o desempenho, em menor expressão, de 10 a 40\% (Mertens, 1994).

Nas situações em que as pastagens nativas constituem a base forrageira e a sua substituição em grande escala normalmente não é viável, a suplementação dos nutrientes limitantes torna-se interessante. As melhores respostas ao uso de suplementação energético-protéica ocorrem quando existe grande disponibilidade de forragem de baixa qualidade, ou seja, com baixo teor protéico, alto teor de fibra e digestibilidade moderada a média (Siebert \& Hunter, 1982), o que parece ser o caso das pastagens nativas entre a primavera e o outono, uma vez que, no inverno, a disponibilidade de pastagem decresce acentuadamente. Outra situação em que as respostas à suplementação são expressivas é quando a quantidade de forragem disponível é reduzida. Neste caso, independentemente do teor de fibra ou de proteína da forragem, os nutrientes fornecidos pela suplementação aumentarão o desempenho animal (Siebert \& Hunter, 1982). Vários trabalhos com pastagens de estação quente, examinando o efeito de suplementos energético-protéicos, foram realizados, porém, testando apenas um ou dois níveis, impossibilitando a obtenção de curvas de resposta. Todavia, infere-se que ofornecimento de suplementos energético-protéicos a silagens e forragens de baixa qualidade permitem ganho de peso adicionais de 200 a 300 g/dia (Poppi \& McLennan, 1995).

Este trabalho foi conduzido com o objetivo de avaliar o efeito do uso de níveis crescentes de suplemento energético sobre o ganho de peso de novilhos de corte.

\section{Material e Métodos}

O experimento foi desenvolvido na Fazenda São José, propriedade da Parceria Agropecuaria Piratini, situada no município de Cerrito, sudoeste do Rio
Grande do Sul, latitude-31,85639e longitude-52,81278, no período de 13 de agosto a 23 de novembro de 1999. A área total do experimento foi de aproximadamente 17,5 hectares, dividida em três piquetes de 5,8,5,7 e 6,3 ha. O experimento consistiu de três períodos experimentais com duração de 28,38 e 35 dias. As médias mensais de temperatura e precipitação durante a fase experimental foram $16,6^{\circ} \mathrm{C}$ e $93,8 \mathrm{~mm}$, respectivamente. Os valores médios relativos aos períodos experimentais encontram-se na Tabela 1.

Foram utilizados 65 bezerros de corte não-castrados, sem raça definida (idade média de 12 meses e peso vivo médio ao início do experimento de $140 \pm 16 \mathrm{~kg}$ ), provenientes da região de Santa Vitória do Palmar, caracteristicamente sem carrapatos. Os novilhos foram pré-imunizados contra a "tristeza parasitária", tratados com vitaminas A e E e desparasitados antes do início da fase experimental assim que chegaram à propriedade.

Os animais foram mantidos em uma pastagem natural melhorada com a sobre-semeadura de Lotus subbiflorus (cornichão el rincon) realizada na primavera de 1998. A pastagem nativa foi composta predominantemente por Axonopus afinis (grama tapete) e Paspalum notatum (grama forquilha), além da participação de Cynodon dactylon (grama seda) e Eragrostis planna (capim-anonni 2). O solo apresentou a seguinte composição físico-química: $21,3 \%$ de argila, $\mathrm{pH}$ de 4,9, 2,72\% de matéria orgânica, $6,63 \mathrm{mg} / \mathrm{dm}^{3}$ de fósforo, $41 \mathrm{mg} / \mathrm{dm}^{3}$ de potássio e $52 \mathrm{mg} / \mathrm{dm}^{3}$ de sódio, $1 \mathrm{cmolc} / \mathrm{dm}^{3}$ de alumínio, $2 \mathrm{cmolc} / \mathrm{dm}^{3}$ de cálcio e $0,7 \mathrm{cmolc} / \mathrm{dm}^{3}$ de magnésio (Tedesco et al., 1995).

Os tratamentos consistiram de controle ou sem suplemento (T0) e de dois níveis de grão de sorgo moído fornecidos em quantidades equivalentes a $0,75 \%(\mathrm{~T} 0,75)$ e $1,5 \%$ do peso vivo $(\mathrm{T} 1,5)$. Estas quantidades foram determinadas por ocasião das pesagens dos animais, realizadas no início de cada período experimental. A composição química média do grão de sorgo utilizado foi de MS 94,2\%, cinzas $2,83 \%$, PB $8 \%$, FDN $45 \%$ e FDA $10 \%$.

O suplemento foi fornecido diariamente às 14:00 horas, colocado em cochos de madeira nos piquetes, com espaço de $45 \mathrm{~cm}$ por animal. No dia seguinte, os cochos eram limpos e verificadas as sobras antes do novo fornecimento, as quais eram pesadas. Os animais tiveram acesso livre a sal mineral e água.

Utilizou-se o pastejo contínuo com lotação variável. Os animais foram manejados em três grupos de 25, 21

\footnotetext{
R. Bras. Zootec., v.34, n.1, p.159-166, 2005
} 
e 19 animais testes em cada lote, respectivamente, para os tratamentos controle, T0,75 e T1,5. Destinou-se um piquete para cada grupo. Durante a condução do experimento, procurou-se manter resíduo médio de forragem de 8 a $10 \mathrm{~cm}$ de altura, carga animal inicial aproximada de $1.466 \mathrm{~kg} / \mathrm{ha}$ e oferta diária de forragem aproximadamente de 7 a $10 \mathrm{~kg}$ de MS por $100 \mathrm{~kg}$ de peso vivo. Além dos animais teste, que permaneceram nos piquetes durante todo o experimento, foram utilizados outros 149 , como reguladores da carga, utilizando-se como critério a manutenção de oferta de forragem semelhante nos três tratamentos.

As pesagens dos animais foram realizadas ao inicio de cada período e no final do experimento, às 8h, após 14 horas de jejum completo.

Foi determinada a quantidade de pasto de cada piquete ao início e final de cada período, segundo o método da dupla amostragem (Wilm et al., 1944), usando 10 amostras cortadas e 100 leituras aleatórias do disco calibrado, em transectas, conforme a área do piquete. O corte das amostras foi feito com tesouras de esquilar, rente ao solo, mas acima da fração do mantilho, usando-se um círculo de ferro com área de $0,088 \mathrm{~m}^{2}$. A partir das 10 amostras cortadas foi calculada uma equação de regressão que relacionou a altura medida com o disco e a quantidade de matéria seca das amostras. O cálculo da quantidade de matéria seca do piquete foi feito pela colocação do valor da altura média das 100 amostras registradas com o disco na equação de regressão. Para cada período e piquete foi calculada uma nova equação de regressão, em decorrência das modificações na fenologia das plantas e da própria composição botânica. As amostras colhidas foram secas em estufa com ventilação forçada a $60^{\circ} \mathrm{C}$, por 48 horas, e pesadas, determinando, assim, a porcentagem de MS do material para os cálculos posteriores.

A taxa de acúmulo de forragem foi calculada utilizando o método de gaiolas de exclusão de pastejo (Gardner, 1986). Colocaram-se três gaiolas em cada piquete e demarcaram-se duas áreas idênticas: uma das áreas foi cortada rente ao chão, usando um círculo de $0,088 \mathrm{~m}^{2}$, onde foi colocada a gaiola. Deixou-se a outra como ponto de referência para a escolha da nova área para o início do período seguinte. Ao final de cada período, a área demarcada dentro da gaiola foi cortada, pesada verde, seca em estufa, a $60^{\circ} \mathrm{C}$, durante 48 horas, e pesada novamente. A taxa de acúmulo de forragem $(\mathrm{kg} / \mathrm{ha} / \mathrm{dia})$ foi calculada dividindo a quantidade média de matéria seca, obtida pelo corte nas gaiolas em dois períodos sucessivos, pelo número de dias de cada período experimental.

Foi determinada a composição química do pasto disponível e daquele obtido por simulação de pastejo. As porcentagens de matéria seca (MS), cinzas (MM), matéria orgânica $(\mathrm{MO})$ e proteína bruta $(\mathrm{PB})$ foram determinadas segundo o AOAC (1975) e as porcentagens de fibra em detergente neutro (FDN) e fibra em detergente ácido (FDA), conforme Goering \& Van Soest (1970). As análises de digestibilidade in vitro da matéria seca (DIVMS) e da matéria orgânica (DIVMO), para as amostras obtidas por simulação de pastejo, seguiram a metodologia de Tilley \& Terry (1963). Esta avaliação foi realizada com número variável de amostras colhidas manualmente, durante a atividade de pastejo, próximo aos locais pastejados pelos animais. Em cada período experimental, estas amostras foram coletadas durante dois dias, uma no final da primeira semana e outra no final da terceira semana.

Os animais foram distribuídos aleatoriamente aos tratamentos segundo o delineamento completamente casualizado, em parcelas subdivididas, onde cada animal foi considerado uma unidade experimental e os diferentes períodos foram considerados como subparcelas. O termo de erro para testar o efeito de tratamento foi animal dentro de tratamento. Como a interação entre tratamentos e períodos foi significativa, analisaram-se os dados dentro de cada período experimental. Usou-se o teste de DMS de Fisher na opção Lsmeans do programa SAS (1989) para efetuar a separação das médias. Em cada período experimental, os valores médios de ganho de peso médio diário foram submetidos à análise de regressão, considerando o seu componente linear, usando o procedimento REG do SAS (1989). Os atributos químicos e produtivos das pastagens em cada período experimental foram submetidos à análise descritiva, obtendo-se as médias e os erros-padrão.

\section{Resultados e Discussão}

Os valores de oferta, disponibilidade inicial e final do pasto e carga animal são apresentados na Tabela 2. Apesar de não ter sido possível realizar análise da variância dos atributos da pastagem, pode-se constatar que estes diferiram numericamente, de acordo com o período experimental avaliado. No período 1 , as disponibilidades inicial e final de forragem foram maiores em comparação aos demais períodos, constatando-se

R. Bras. Zootec., v.34, n.1, p.159-166, 2005 
tendência de redução na massa de forragem, com o avanço dos períodos. A taxa de acúmulo foi maior no segundo período. A oferta de matéria seca de forragem foi relativamente constante, graças ao uso de lotação variável, com a colocação e retirada dos animais reguladores, a fim de manter a oferta em torno de $10 \%$. Houve redução expressiva da carga média do primeiro ao último período, em função da redução da área útil dos piquetes, que decorreu das precipitações nos primeiros dois períodos (Tabela 1), o que foi agravado pelo tipo de solo, constituído por argila 2:1 e de baixa permeabilidade. No último período, a redução de carga foi motivada pela estiagem (Tabela 1).

As quantidades de forragem apresentadas na Tabela 2 situam-se acima dos $1.000 \mathrm{~kg}$ MS/ha referidos por Poppi et al. (1987) como limitantes do consumo, juntamente com a oferta média de MS $(9,54 \mathrm{~kg} \mathrm{MS} / 100 \mathrm{~kg}$ PV). No entanto, estas quantidades foram estimadas sem descontar a área do piquete que ficou submersa, especialmente durante o período 2 , o que provavelmente limitou o consumo de forragem dos animais. A oferta de MS estimada situouse abaixo dos valores que permitem a ingestão máxima de forragem em campo natural, que, de acordo com Moojen (1991) e Correa (1993), variaram entre 12 e $16 \mathrm{~kg} \mathrm{MS} / 100 \mathrm{~kg}$ PV, para pastagens nativas da Depressão Central do Rio Grande do Sul.

Observa-se que o valor médio de leitura do disco calibrado decresceu com o avanço dos períodos experimentais (Tabela 2) e, embora a quantidade de matéria seca de forragem ficasse acima de $1.000 \mathrm{~kg}$ $\mathrm{MS} / \mathrm{ha}$, este valor indica que a altura do pasto reduziu bastante, podendo efetivamente ter prejudicado a ingestão dos animais.

Os valores da composição química da forragem disponível e daquela colhida manualmente simulando a atividade de pastejo dos animais são apresentados, respectivamente, nas Tabelas 3 e 4 . Observam-se valores elevados de matéria mineral, provavelmente em decorrência da contaminação das amostras com solo, em virtude do alagamento e, após, da camada de lama seca que se depositou, respectivamente, durante o segundo e terceiro períodos do experimento. Os teores de PB, FDN e FDA evidenciam a qualidade da pastagem, resultado superior ao obtido para pastagem natural nesta mesma época do ano, em razão da presença do cornichão. Valores reportados por Souza (1989), Moojen (1991) e Correa (1993) mostram valores inferiores de PB e superiores de FDN e de
Tabela 1 - Dados de precipitação e temperaturas médias para cada período

Table 1 - Mean values of rainfall and temperature for each period

\begin{tabular}{lcc}
\hline & \multicolumn{2}{c}{$\begin{array}{c}\text { Variáveis climáticas } \\
\text { Climate variables }\end{array}$} \\
\cline { 2 - 3 } Período & $\begin{array}{c}\text { Precipitação }(\mathrm{mm}) \\
\text { Period }\end{array}$ & $\begin{array}{c}\text { Temperatura }\left({ }^{\circ} \mathrm{C}\right) \\
\text { Temperature }\end{array}$ \\
\hline $1(13 / 8$ a 9/9) & 158,2 & 14,4 \\
$2(10 / 9$ a $18 / 10)$ & 101,0 & 15,1 \\
$3(19 / 10$ a 22/11 $)$ & 22,3 & 19,0 \\
\hline
\end{tabular}

Tabela 2 - Disponibilidade de matéria seca inicial (DISPIMS) e final (DISPFMS) da pastagem ( $\mathrm{kg} / \mathrm{ha})$, taxa de acúmulo de pastagem ( $\mathrm{kg} / \mathrm{ha} / \mathrm{dia})$ (TXACUM), oferta ( $\mathrm{kg} \mathrm{MS/100} \mathrm{kg} \mathrm{de} \mathrm{peso} \mathrm{vivo/}$ dia), carga (kg peso vivo/ha) e valor médio da leitura com disco $(\mathrm{cm})$. Os erros-padrão das médias são apresentados nos parênteses

Table 2 - Initial herbage mass (IHM), residual herbage mass (RHM) (kg/ha), pasture growth rate (PGR) ( $\mathrm{kg} / \mathrm{ha}$ day), pasture availability (PA) ( $\mathrm{kg} D M / 100 \mathrm{~kg} L W /$ day), stocking rate ( $\mathrm{kg}$ of $\mathrm{LW} / \mathrm{ha}$ ) and mean value of plate meter $(\mathrm{cm})$. Standard errors of the mean are shown in the brackets

\begin{tabular}{lcllllll}
\hline & \multicolumn{2}{c}{$\begin{array}{c}\text { Tratamentos } \\
\text { Treatments }\end{array}$} & & & \multicolumn{3}{c}{$\begin{array}{c}\text { Períodos } \\
\text { Periods }\end{array}$} \\
\cline { 2 - 3 } \cline { 4 - 7 } Atributos & 0 & 0,75 & 1,5 & & 1 & 2 & 3
\end{tabular}

Attributes

\begin{tabular}{lcccccc}
\hline DISPIMS & 2093 & 2141 & 2144 & 3120 & 1731 & 1526 \\
IHM & $(469)$ & $(627)$ & $(408)$ & $(132,17)$ & $(56,40)$ & $(84,1)$ \\
DISPFMS & 1505 & 1546 & 1659 & 1731 & 1526 & 1453 \\
RHM & $(123)$ & $(96)$ & $(101)$ & $(56,40)$ & $(84,10)$ & $(98,17)$ \\
TX ACUM & 43,39 & 36,67 & 35,32 & 28,20 & 55,10 & 32,10 \\
PGR & $(9,61)$ & $(9,20)$ & $(6,74)$ & $(0,99)$ & $(3,65)$ & $(4,09)$ \\
OFERTA & 10,39 & 9,64 & 8,58 & 9,68 & 8,40 & 10,53 \\
PA & $(1,03)$ & $(1,01)$ & $(0,36)$ & $(0,24)$ & $(43,84)$ & $(1,29)$ \\
CARGA & 1087 & 1117 & 1178 & 1442 & 1202 & 738 \\
$\begin{array}{l}\text { Stocking rate } \\
\text { Leitura do }\end{array}$ & $(213)$ & $(259)$ & $(155)$ & $(13)$ & $(44)$ & $(94)$ \\
$\begin{array}{l}\text { disco (cm) } \\
\text { Plate meter records }\end{array}$ & 3,21 & 3,64 & 3,35 & 5,07 & 3,30 & 1,73 \\
\hline
\end{tabular}

${ }^{1} \mathrm{T0}=$ controle; $\mathrm{T0}, 75=0,75 \%$ do peso vivo de sorgo moído; $\mathrm{T} 1,5=1,5 \%$ do peso vivo de sorgo moído.

${ }^{1} \mathrm{TO}=$ control; $\mathrm{TO}, 75=0.75 \%$ of live weight of ground sorghum grain; $T 1,5=1.5 \%$ of live weight of ground sorghum grain.

FDA, em relação aos encontrados no presente trabalho. Pardo Patiño (2001) suplementou bovinos na mesma área experimental e encontrou valores semelhantes de PB, mas valores superiores para FDN e FDA, em relação ao presente trabalho, provavelmente em função do decréscimo da participação do cornichão e aumento de Eragrostis planna (capim-anonni 2). 
Tabela 3 - Valores médios da porcentagem de matéria seca (MS), cinzas (MM), proteína bruta (PB), fibra em detergente neutro (FDN) e fibra em detergente ácido (FDA) no pasto disponível, por tratamento e por período. Os erros-padrão das médias são apresentados nos parênteses

Table 3 - Means values of dry matter (DM), ash, crude protein (CP), neutral detergent fiber (NDF) and acid detergent fiber (ADF) percentages of the available pasture per treatment e per period. Standard errors of the mean are shown in the brackets

\begin{tabular}{|c|c|c|c|c|c|c|}
\hline \multirow[b]{2}{*}{$\begin{array}{l}\text { Atributos } \\
\text { Attributes }\end{array}$} & \multicolumn{3}{|c|}{$\begin{array}{c}\text { Tratamentos } 1 \\
\text { Treatments }\end{array}$} & \multicolumn{3}{|c|}{$\begin{array}{l}\text { Períodos } \\
\text { Periods }\end{array}$} \\
\hline & 0 & 0,75 & 1,5 & 1 & 2 & 3 \\
\hline MS & 29,31 & 21,74 & 26,52 & 21,4 & 25,02 & 31,16 \\
\hline$D M$ & $(3,19)$ & $(3,7)$ & $(1,85)$ & $(2,08)$ & $(3,19)$ & $(1,76)$ \\
\hline MM & 29,88 & 20,15 & 22,84 & 15,42 & 31,36 & 26,08 \\
\hline$A S H$ & $(6,57)$ & $(3,61)$ & $(3,99)$ & $(1,02)$ & $(3,74)$ & $(4,04)$ \\
\hline PB & 10,09 & 14,39 & 12,39 & 11,53 & 11,67 & 13,67 \\
\hline$C P$ & $(0,63)$ & $(0,29)$ & $(1,21)$ & $(1,52)$ & $(1,20)$ & $(1,18)$ \\
\hline FDN & 56,11 & 54,93 & 56,05 & 52,75 & 59,5 & 54,83 \\
\hline$N D F$ & $(2,01)$ & $(2,79)$ & $(1,57)$ & $(1,55)$ & $(0,23)$ & $(0,55)$ \\
\hline FDA & 36,54 & 32,51 & 33,67 & 31,38 & 38,36 & 32,99 \\
\hline$A D F$ & $(3,76)$ & $(0,94)$ & $(1,65)$ & $(0,18)$ & $(2,79)$ & $(0,93)$ \\
\hline
\end{tabular}

Comparando-se os valores de PB, FDN e FDA da pastagem disponível (Tabela 3) e aquela colhida manualmente simulando o pastejo dos animais (Tabela 4), observa-se a melhor qualidade da última, em razão da seleção pelos animais por plantas e partes de plantas com melhor qualidade que aquela disponível (Hodgson, 1990; Walker, 1995).

O ganho diário de peso (GDP) dos lotes variou entre tratamentos e períodos. Todavia, como foram constatadas interações significativas entre os níveis do suplemento energético e períodos, a análise do efeito dos tratamentos foi realizada dentro de cada período experimental (Tabela 5).

No período 1, caracterizado pela boa qualidade e alta disponibilidade da pastagem, não houve diferenças entre os dois níveis de suplementação 0,75 e 1,5\% $(\mathrm{P}>0,05)$, mas os animais que receberam suplemento ganharam mais peso que os não-suplementados $(\mathrm{P}<0,05)$.

Este resultado está de acordo com os de Pardo Patiño (2001), que forneceu as mesmas quantidades de grão de sorgo, que no presente trabalho. O autor observou efeito quadrático dos níveis de suplementação, onde os animais suplementados ganharam mais peso que os não suplementados, mas não observou diferença de desempenho entre os níveis 0,75 e $1,5 \%$ do PV. Restle et al. (1999) suplementaram
Tabela 4 - Valores percentuais médios de qualidade química do pasto, obtidos por simulação de pastejo, de matéria mineral (MM), proteína bruta (PB), fibra em detergente neutro (FDN), fibra em detergente ácido (FDA), digestibilidade in vitro da matéria seca (DIVMS) e digestibilidade in vitro da matéria orgânica (DIVMO), em cada período. Os erros-padrão das médias são apresentados entre parênteses

Table 4 - Means of chemical quality of hand plucking pasture, in percentage of ash, crude protein (CP), NDF, $A D F$, in vitro digestibility of dry matter (IVDDM), in vitro digestibility of organic matter (IVDOM) for each period. Standard errors of the mean are shown in the brackets

\begin{tabular}{|c|c|c|c|c|c|c|}
\hline \multirow[b]{2}{*}{$\begin{array}{l}\text { Atributos } \\
\text { Attributes }\end{array}$} & \multicolumn{3}{|c|}{$\begin{array}{c}\text { Tratamentos } \\
\text { Treatments }\end{array}$} & \multicolumn{3}{|c|}{$\begin{array}{l}\text { Períodos } \\
\text { Periods }\end{array}$} \\
\hline & 0 & 0,75 & 1,5 & 1 & 2 & 3 \\
\hline$\overline{\mathrm{MM}}$ & 24,86 & 25,02 & 20,58 & $\mathrm{Nd} 2$ & 32,16 & 14,80 \\
\hline$A S H$ & $(9,38)$ & $(9,78)$ & $(6,89)$ & & $(2,36)$ & $(0,56)$ \\
\hline PB & 13,36 & 16,37 & 17,26 & $\mathrm{Nd}$ & 13,86 & 17,46 \\
\hline$C P$ & $(1,85)$ & $(1,87)$ & $(1,69)$ & & $(1,21)$ & $(1,14)$ \\
\hline FDN & 53,88 & 45,21 & 48,46 & $\mathrm{Nd}$ & 47,45 & 51,03 \\
\hline$N D F$ & $(0,99)$ & $(0,80)$ & $(3,76)$ & & $(2,78)$ & $(2,62)$ \\
\hline FDA & 34,73 & 32,64 & 35,07 & $\mathrm{Nd}$ & 32,45 & 35,84 \\
\hline$A D F$ & $(0,71)$ & $(2,47)$ & $(1,92)$ & & $(1,17)$ & $(0,58)$ \\
\hline DIVMS & 42,34 & 48,78 & 46,14 & $\mathrm{Nd}$ & 41,50 & 50,00 \\
\hline$I V D D M$ & $(8,66)$ & $(3,48)$ & $(0,62)$ & & $(3,91)$ & $(1,67)$ \\
\hline DIVMO & 54,05 & 58,27 & 53,55 & $\mathrm{Nd}$ & 56,56 & 54,01 \\
\hline IVDOM & $(3,40)$ & $(2,44)$ & $(4,78)$ & & $(3,03)$ & $(2,66)$ \\
\hline
\end{tabular}

1 T0 = controle; T0,75 =0,75\% do peso vivo de sorgo moído; $\mathrm{T} 1,5=1,5 \%$ do peso vivo de sorgo moído.

$1 \mathrm{TO}=$ control; TO.75 $=.75 \%$ of live weight of ground sorghum grain; $T 1.5=1.5 \%$ of live weight of ground sorghum grain.

2 Não determinado (Not determinated).

novilhos de corte com grão de milho moído e não encontraram diferenças no GPD $(\mathrm{P}>0,05)$ para os níveis de 0,5 e $1,0 \%$ do PV, em razão do efeito de substituição de suplemento por pastagem. Frizzo et al. (2003) também não constataram diferenças de ganho de peso de novilhas entre os níveis de suplementação energética 0,7 e $1,4 \%$ do peso vivo.

Efeito negativo de doses altas de amido sobre a digestibilidade da fibra da forragem também pode ter contribuído para estes resultados. Este efeito foi verificado por Garcés-Yepez et al. (1997), Ferrel et al. (1999) e Philippeau et al. (1999), que observaram que doses altas de amido (50 e $25 \%$ da exigência de NDT) tiveram efeitos associativos negativos sobre a digestão, provocado pelas mudanças no ecossistema ruminal. Segundo Hoover (1999), em pastagens de baixa qualidade, doses de grãos maiores que $30 \%$ da MS consumida podem deprimir a digestibilidade da fibra. Galloway et al. (1993) encontraram o mesmo 
efeito depressor do amido sobre a digestão da fibra nas estações de inverno e verão, quando o suplemento energético foi fornecido em doses superiores a $0,5 \%$ do PV. Entretanto, esta diminuição na digestibilidade da fibra não foi observada por Elizalde et al. (1999), que suplementaram novilhos em pastagem de alfafa e encontraram resposta linear entre o consumo de milho e o consumo de forragem.

No presente trabalho, o suplemento de sorgo nos níveis de 0,75 e 1,5\% correspondeu, respectivamente, a 23 e $47 \%$ das exigências de NDT e a $42 \%$ da matéria seca necessária para promover ganho de peso em torno de $0,90 \mathrm{~kg} / \mathrm{dia}$ (Tabela 6), o que pode ter causado efeito negativo sobre a digestão da fibra.

No período 2, não se constataram diferenças entre os níveis de suplementação ( $\mathrm{P}>0,05)$, obtendo-se GPD médio de 0,24 kg (Tabela 5), semelhantemente ao reportado por Jacques (1999) nesta época do ano, mas inferior ao encontrado por Pardo Patiño (2001), cujo valor médio para esta época do ano foi de $0,38 \mathrm{~kg} / \mathrm{dia}$.

Este período apresentou os menores valores numéricos de oferta de forragem e maiores valores de FDN e FDA na pastagem disponível. Além disso, os piquetes permaneceram alagados por mais tempo, o que pode ter limitado sensivelmente o consumo. Embora o comportamento dos animais não tenha sido avaliado, observou-se que, durante esse período, os animais caminharam muito por todo o piquete, em busca de áreas mais secas, o que pode ter elevado seu gasto energético com mantença.

No período 3, o GPD aumentou linearmente com os níveis de suplemento (Tabela 5). Restle et al. (2001) também verificaram aumento linear de ganho de peso de vacas de corte em pastagem cultivada de aveia e azevém, não suplementadas e suplementadas com 0,4 e $0,8 \%$ do peso vivo.

O período 3 caracterizou-se pela menor disponibilidade de forragem e menor altura decorrente da estiagem (Tabela 1). O consumo de forragem provavelmente foi limitado, principalmente, por fatores não-nutricionais (Poppi et al., 1987), e os nutrientes fornecidos pelo suplemento influenciaram o ganho de peso.

Quando se consideraram os valores médios do experimento, verificou-se que o GPD aumentou linearmente com os níveis de suplementação $\left(\mathrm{Y}=0,38+0,23 \mathrm{x}, \mathrm{P}=0,09 ; \mathrm{r}^{2}=0,98\right)$. No entanto, Pardo Patiño (2001), ao trabalhar na mesma área e com os mesmos níveis de suplementação, encontrou relação quadrática entre GPD e os níveis de suplementação, provavelmente em decorrência da degradação da pastagem, que foi invadida por Eragrostis planna.

Na Tabela 7, são apresentados os custos com produção para cada tratamento, durante 90 dias, para animais com peso inicial de $140 \mathrm{~kg}$.

O nível de suplementação $0,75 \%$, teve a maior resposta econômica, com um ganho por animal, de US $\$ 5,32$, vs. 3,72 e 3,86 para o controle e o nível 1,5\%, respectivamente, representando ganho $42,88 \%$ maior com relação ao controle. Estes ganhos são reflexo da maior carga praticada nos lotes suplementados durante o período experimental e do maior GPD encontrados nos períodos 1 e 3, para os animais suplementados.

Rocha et al. (2001), ao estudarem a viabilidade econômica da prática da suplementação de pastagens

Tabela 5 - Médias e equações de regressão para ganho de peso diário (GPD, em kg/dia) em função dos níveis de suplementação ( $x$, em porcentagem do peso vivo) para cada período

Table 5 - Means and regression equations for average daily gain (ADG) $(\mathrm{kg})$ related to energy supplement levels ( $X$ as live weight percentage) at each experimental period

\begin{tabular}{|c|c|c|c|c|}
\hline \multirow[t]{2}{*}{$\begin{array}{l}\text { Períodos } \\
\text { Periods }\end{array}$} & \multicolumn{3}{|c|}{$\begin{array}{l}\text { Tratamentos } \\
\text { Treatments }^{1}\end{array}$} & \multirow[t]{2}{*}{$\begin{array}{l}\text { Equações de regressão } \\
\text { Regression equations }\end{array}$} \\
\hline & T0 & $\mathrm{T} 0,75$ & $\mathrm{~T} 1,5$ & \\
\hline $1(13 / 08$ a $9 / 09)$ & $0,423 b$ & $0,911 \mathrm{a}$ & $0,827 \mathrm{a}$ & $\begin{array}{l}Y=0,42+1,03 \mathrm{x}-0,51 \mathrm{x}^{2} \\
\mathrm{P}=0,0212 ; \mathrm{r}^{2}=0,20\end{array}$ \\
\hline $2(10 / 09$ a $18 / 10)$ & $0,251 \mathrm{a}$ & $0,230 \mathrm{a}$ & $0,244 \mathrm{a}$ & $Y=0,24$ \\
\hline $3(19 / 10$ a $22 / 11)$ & $0,418 b$ & $0,583 b$ & $1,04 \mathrm{a}$ & $\begin{array}{l}Y=0,37+0,41 \mathrm{x} \\
\mathrm{P}=0,16 ; \mathrm{r}^{2}=0,93\end{array}$ \\
\hline Média (mean) & $0,364 c$ & $0,575 b$ & $0,704 a$ & $\begin{array}{l}Y=0,38+0,23 \mathrm{x} \\
\mathrm{P}=0,09 ; \mathrm{r}^{2}=0,98\end{array}$ \\
\hline
\end{tabular}

\footnotetext{
1 T0 = controle; T0,75 = 0,75\% do peso vivo de sorgo moído; T1,5 =1,5\% do peso vivo de sorgo moído.

${ }_{1} \mathrm{TO}=$ control; $T 0,75=.75 \%$ of live weight of ground sorghum grain; $T 1,5=1.5 \%$ of live weight of ground sorghum grain

a,b,c médias na mesma linha seguidas por letras distintas diferem estatisticamente pelo teste DMS Fisher, Lsmeans $(P<0,05)$.

$a, b, c$ means in the same row followed by distinct letters are statistically different according to DMS Fisher test, Lsmeans $(P<.05)$.
}

\section{R. Bras. Zootec., v.34, n.1, p.159-166, 2005}


Tabela 6 - Estimativas das exigências nutricionais dos animais com peso de $140 \mathrm{~kg}$, em $\mathrm{kg}$ por dia e como \% do consumo previsto, segundo o NRC (1996) e das contribuições nutritivas do suplemento

Table 6 - Nutritional requirements estimates according to NRC (1996) for steers with $140 \mathrm{~kg}$ and nutritive contributions from supplement

\begin{tabular}{|c|c|c|c|c|c|c|}
\hline & \multicolumn{3}{|c|}{ GPD 0,4 kg (ADG 0.4 kg) } & \multicolumn{3}{|c|}{ GPD 0,9 kg (ADG 0.9 kg) } \\
\hline & $\mathrm{MS}(D M)$ & $\mathrm{PB}(C P)$ & $\operatorname{NDT}(T D N)$ & $\mathrm{MS}(D M)$ & $\mathrm{PB}(C P)$ & $\operatorname{NDT}(T D N)$ \\
\hline Exigências (kg/dia e \% MS) & 4,24 & 0,44 & 2,43 & 5,00 & 0,67 & 3,79 \\
\hline Requirements $^{1}$ (kg/day and \% DM) & 10,38 & 57,31 & 13,40 & 75,80 & & \\
\hline Fornecido pelo suplemento $\mathrm{T} 0,75$ & 1,05 & 0,08 & 0,80 & 1,05 & 0,08 & 0,80 \\
\hline $\begin{array}{l}\text { Supplement contribution T0.75 } \\
\text { T0,75 (Exigência - Fornecido) } \\
\text { T0.75 (Requirements - Supplement) }\end{array}$ & 3,22 & 0,36 & 1,63 & 3,95 & 0,59 & 2,99 \\
\hline $\begin{array}{l}\text { Fornecido por suplemento T1,5 } \\
\text { Supplement contribution T1.5 }\end{array}$ & 2,10 & 0,17 & 1,58 & 2,10 & 0,17 & 1,58 \\
\hline $\begin{array}{l}\text { T1,5 (Exigência-Fornecido) } \\
\text { T1.5 (Requirements - Supplement) }\end{array}$ & 2,14 & 0,27 & 0,85 & 2,90 & 0,50 & 2,21 \\
\hline
\end{tabular}

Tabela 7 - Custos de produção (US \$) de um bezerro com PV inicial de $140 \mathrm{~kg}$, em um período de 90 dias (US $\$ 1=\$ 2,38$ Reais)

Table 7 - Production cost (US \$) for steer (140 kg inicial LW) on a 90 -d period (US $\$ 1=\$ 2,38$ Reais)

\begin{tabular}{|c|c|c|c|}
\hline \multirow[t]{3}{*}{ Item } & \multicolumn{3}{|c|}{ Tratamento $^{1}$ (Treatment $^{1}$ ) } \\
\hline & T0 & $\mathrm{T} 0,75$ & $\mathrm{~T} 1,5$ \\
\hline & Valor US \$ & Valor US \$ & Valor US \$ \\
\hline $\begin{array}{l}\text { Animal } 140 \mathrm{~kg} \\
\text { Steer }\end{array}$ & 68,82 & 68,82 & 68,82 \\
\hline Ração & 0,00 & 7,02 & 13,58 \\
\hline $\begin{array}{l}\text { Supplement } \\
\text { Frete }\end{array}$ & 0,56 & 0,56 & 0,56 \\
\hline $\begin{array}{l}\text { Transport } \\
\text { Mantença cerca } \\
\text { Maintainfence }\end{array}$ & 0,18 & 0,18 & 0,18 \\
\hline $\begin{array}{l}\text { Medicamentos } \\
\text { Medicament }\end{array}$ & 1,63 & 1,63 & 1,63 \\
\hline $\begin{array}{l}\text { Sal mineral } \\
\text { Mineral salt }\end{array}$ & 2,74 & 2,74 & 2,74 \\
\hline $\begin{array}{l}\text { Mão-de-obra } \\
\text { Manual job }\end{array}$ & 0,73 & 0,87 & 1,02 \\
\hline $\begin{array}{l}\text { Arrendamento } \\
\text { Renting tenure }\end{array}$ & 1,01 & 1,01 & 1,01 \\
\hline $\begin{array}{l}\text { Outros } \\
\text { Others }\end{array}$ & 1,89 & 2,07 & 2,24 \\
\hline Total & 77,56 & 84,92 & 91,79 \\
\hline $\begin{array}{l}\text { Total } \\
\text { Venda } \\
\text { Sale }\end{array}$ & 81,29 & 90,23 & 95,65 \\
\hline $\begin{array}{l}\text { Diferença/animal } \\
\text { Difference/animal }\end{array}$ & 3,72 & 5,32 & 3,86 \\
\hline $\begin{array}{l}\text { Ganho/ha } \\
\text { Gain/ha }\end{array}$ & 28,89 & 100,64 & 32,47 \\
\hline
\end{tabular}

1 T0 $=$ controle; T0,75 $=0,75 \%$ do peso vivo de sorgo moído; $\mathrm{T} 1,5=1,5 \%$ do peso vivo de sorgo moído.

$1 \mathrm{TO}=$ control; TO,75 $=.75 \%$ of live weight of ground sorgum grain; $T 1.5=1.5 \%$ of live weight of ground sorghum grain cultivadas de aveia e azevém, verificaram que o controle e o nível intermediário de suplementação ( $0,7 \%$ do peso vivo) permitiram as maiores margens, enquanto o nível alto de suplementação $(1,4 \%$ do peso vivo) permitiu uma margem muito menor, respectivamente $135,1,136,3$ e 22,3 equivalentes de $\mathrm{kg}$ de boi gordo na região de Santa Maria (RS), ainda que o ganho de peso vivo por área dos animais suplementados tenha sido bem maior, de 424, 536 e $671 \mathrm{~kg} / \mathrm{ha}$, respectivamente, para os níveis $0,0,7$ e $1,4 \%$ do peso vivo de uma mistura de $50 \%$ farelo de arroz e 50\% polpa cítrica.

\section{Conclusões}

A suplementação energética aumentou o GPD de novilhos mantidos em pastagem nativa melhorada. A sustentabilidade do sistema foi maior com nível intermediário de suplementação, pois permitiu a maior margem.

\section{Literatura Citada}

ABDALLA, H.O.; FOX, D.G.; SEANEY, R.R. et al. Variation in protein and fibers fractions in pasture during the grazing season. Journal of Animal Science, v.66, p.2663-2667, 1988.

ASSOCIATION OF OFFICIAL ANALITICAL CHEMIST AOAC. Official methods of analysis. 12.ed. Washington, D.C.: 1975. 1094p.

CORREA, F.L. Produção e qualidade de uma pastagem nativa sob níveis de oferta de pastagem a novilhos. Porto Alegre: Universidade Federal de Rio Grande do Sul, 1993. 167p. Dissertação (Mestrado em Zootecnia) - Universidade 
Federal de Rio Grande do Sul, 1993.

ELIZALDE, J.C.; MERCHEN, N.R.; FOULKNER, D.B. Supplemental cracked corn for steers fed fresh alfalfa: I. Effects on digestion of organic matter fiber and starch. Journal of Animal Science, v.77, n.2, p.457-466, 1999.

FERREL, C.L.; KREIKEMEIER, J.; FREETLY, H.C. The effect of supplemental energy, nitrogen and protein on feed intake, digestibility and nitrogen flux across the gut and liver in sheep fed low-quality forage. Journal of Animal Science, v.77, n.12, p.3353-3364, 1999.

FRIZZO, A.; ROCHA, M.G.; RESTLE, J. et al. Efeito de diferentes níveis de suplementação energética no desempenho de bezerras em pastejo. Revista Brasileira de Zootecnia, v.32, n.3, p.643-652, 2003.

GALLOWAY, D.L.; GOETSCH, A.L.; FORSTER JR., L.A. Feed intake and digestibility by cattle consuming bermuda grass or orchard grass hay supplemented with soybean hulls and corn. Journal of Animal Science, v.71, n.11, p.3087-3095, 1993.

GARCÉS-YEPEZ, P.; KUNKLE, W.E.; BOITES, D.B. Effects of supplemental energy source and amount of forage intake and performance by steers and intake and diet digestibility by sheep. Journal of Animal Science, v.75, n.7, p.1918-1925, 1997.

GARDNER, A.L. Técnicas de pesquisa em pastagens e aplicabilidade de resultados en sistemas de produção. Brasil: IICA, 1986. 197p.

GOERING, H.K.; Van SOEST, P.J. Forage fiber analysis (apparatus, reagents, procedures and some aplications). Washington, D.C.: Agriculture Research Service. US Department of Agriculture, 1970. (Agriculture Handbook, 379)

HODGSON, J. Grazing management: science into practice. London: Longman Scientific \& Technical, 1990. 203p.

HOOVER, W.H. Chemical factors involved in ruminal fiber digestion. Journal of Dairy Science, v.69, n.10, p.2755-2766, 1999.

IBGE. 1998. Censo Agropecuário 1995-96. Rio de Janeiro. 366p.

JACQUES, A.V.A. Qualidade da pastagem nativa. In: FEDERACITE, VIII, CADEIAS FORRAGEIRAS REGIONAIS. Porto Alegre: FEDERACITE, 1999. p.117.

JACQUES, A.V.A.; SAIBRO, J.C.; LOBATO, J.F.P. et al. Sistemas de produção de forragens para a Depressão Central/RS. In: FEDERACITE, VI, CADEIAS FORRAGEIRAS REGIONAIS. Porto Alegre: FEDERACITE, 1995. p.13-28.

MERTENS, D.R. Regulation of forage intake. In: FAHEY Jr., G.C. (Ed.) Forage quality, evaluation and utilization. Madison: American Society of Agronomy, 1994. p.450-493.

MOHRDIECK, K.H. Formações campestres do Rio Grande do Sul. In: SEMINÁRIO SOBRE PASTAGENS 'DE QUE PASTAGENS NECESSITAMOS', 1980, Porto Alegre. Anais...Porto Alegre: FARSUL, 1980. p.18-27.

MOOJEN, E.L. Dinâmica e potencial produtivo de uma pastagem nativa do Rio Grande do Sul submetida a pressões de pastejo, época de diferimento e níveis de adubação. Porto Alegre: Universidade Federal de Rio Grande do Sul, 1991. 231p. Tese (Doutorado em Zootecnia) Universidade Federal de Rio Grande do Sul, 1991.

NATIONAL RESEARCH COUNCIL - NRC. Nutrient requirements of beef cattle. 7.ed. Washington, D.C.: National Academic Press, 1996. 242p.

PARDO PATIÑO, R.M. Efeitos de níveis crescentes de suplemento energético em bezerros de corte em pastejo. Pelotas:
Universidade Federal de Pelotas, 2001. 81p. Dissertação (Mestrado em Zootecnia) - Universidade Federal de Pelotas, 2001.

PHILIPPEAU, C.; MARTIN, C.; MICHALET-DOREAU, B. Influence of grain source on ruminal caracteristics and rate, site and extent of digestion in beef steers. Journal of Animal Science, v.77, n.6, p.587-1596, 1999.

PARDO, R.M.P. Efeitos de níveis crescentes de suplemento energético em bezerros de corte em pastejo. Pelotas: UniversidadeFederal de Pelotas, 2001.81p. Dissertação(Mestrado em Zootecnia) - Universidade Federal de Pelotas, 2001.

POPPI, D.P.; HUGHES, T.P.; L'HUILLIER, P.J. Intake of pasture by grazing ruminants. In: NICOL, A.M. (Ed.). Livestock production feeding on pasture. New Zealand: New Zealand Society of Animal Production, 1987. p.55-63. (Occasional Publication, 10)

POPPI, D.P.; McLENNAN, S.R. Protein and energy utilization by ruminants at pasture. Journal of Animal Science, v.73, n.1, p.278-290, 1995.

RESTLE, J.; BACK, M.; BRONDANI, I. et al. Suplementação associada com lasalocida para novilhos em terminação em pastagem cultivada de inverno. Ciência Rural, v.29, n.3, p.555-559, 1999.

RESTLE, J.; VAZ, F.N.; ROSO, C. et al. Desempenho e característica da carcaça de vacas de diferentes grupos genéticos em pastagem cultivada com suplementação energética. Revista Brasileira de Zootecnia, v.30, n.6, p.1813-1823, 2001.

ROCHA, M.G.; PILAU, A.; SANTOS, D.T. et al. Produção animal e retorno econômico da suplementação energética em pastagem cultivada de inverno. In: REUNIÃO ANUAL DA SOCIEDADE BRASILEIRA DE ZOOTECNIA, 38., 2001, Piracicaba. Anais... Piracicaba: Sociedade Brasileira de Zootecnia, 2000. p.198.

STATISTICAL ANALYSIS SYSTEM - SAS. Version for WINRelease 6.11. Cary: 1989.

SIBERT, B.D.; HUNTER, R.A Supplementary feeding of grazing animals. In: HACKER, J.B. (Ed.) Nutritional limits to animal production from pastures. Australia: CSIRO, 1982. p.409-426.

SOUZA, A.G. Evolução e produção animal da pastagem nativa sob pastejo contínuo e rotativo. Porto Alegre: Universidade Federal do Rio Grande do Sul, 1989. 192p. Dissertação (Mestrado em Zootecnia) - Universidade Federal do Rio Grande do Sul, 1989.

TEDESCO, M.J.; GIANELLO, C.; BISSARI, C.A. et al. Análise de solo, plantas e outros materiais. Porto Alegre: Universidade Federal do Rio Grande do Sul, 1995. 174p. (Boletim Técnico)

TILLEY, J.M.; TERRY, R.A. A two-stage technique for the in vitro digestion of forage crops. Journal of British Grassland Society, v.18, n.2, p.104-111, 1963.

Van SOEST, P.J. Nutritional ecology of the ruminant. 2.ed. Ithaca \& London: Cornell University Press, 1994. 476p.

WALKER, J.W. Viewpoint: grazing management and research now and in the next millenium. Journal of Range Management, v.48, n.4, p.350-357, 1995.

WILM, H.G.; COSTELO, D.F.; KLIPPLE, G.E. Estimating forage yield by the double sampling method. Journal of the American Society for Agriculture, v.36, n.1, p.194-203, 1944.

Recebido em: 02/04/03

Aceito em: 21/10/04

R. Bras. Zootec., v.34, n.1, p.159-166, 2005 